\title{
Application and Optimization of Using Recycled Pulp for Methylene Blue Removal from Wastewater: A Response Surface Methodology Approach
}

\author{
Andreas Aditya Hermawan, Tan Kok Bing, and Babak Salamatinia
}

\begin{abstract}
One of the main challenges in the industrial world is presence of dyes in water bodies, which can create lots of problems. Researchers have recently focused a lot on removing dyes by use of low cost techniques or waste material. A huge amount of waste paper is daily produced in many places. This study has been conducted to investigate the possibility of using waste paper as an adsorbent to remove methylene blue (MB) dye from water. With total of six variables observed, the experiment was divided into two parts using central composite design, and employing Response Surface Methodology (RSM) by using Design-Expert 6.0.7 Software. After certain optimization following the criteria from software prediction, the highest removal of $\mathrm{MB}$ was found to be $95 \%$. Pulped waste paper shows good sorption ability and the optimum conditions were found.
\end{abstract}

Index Terms-Renewability, adsorption, methylene blue, paper pulp, response surface methodology.

\section{INTRODUCTION}

In this generation, environmental issues such as water pollution are becoming increasingly significant. One of the many issues that contribute to water pollution is the presence of dye in industrial wastewater. Dyes have been reported to be used by Chinese for the first time in 2600 BC [1]. Ever since, the use of dyes in different industries has significantly increased. Many industries such as paper, plastic, leather and textile industry etc. are amongst the many industries that use dyes to color their products. As a result, these industries produce a substantial amount of colored wastewater (Rafatullah et al., 2010). One of the most commonly used dyes in the industries, and subsequently one of the main contributor to dye wastewater pollution is methylene blue (MB) [2].

While it is commonly used, many people do not understand the effect of MB exposure. Even the dye concentration of $\mathrm{MB}$ is as low as $1 \mathrm{ppm}$, the color is not only highly visible, but exposure to MB may affect the flora and fauna directly due to the water eutrophication, which will endanger their growth. Direct contact to animal's eye will cause eye-burn as well, and result in a permanent injury [3]. Same case could happen to human health as well regarding the direct contact to visual senses. Nevertheless, there are

Manuscript received April 5, 2014; revised July 19, 2014.

A. A. Hermawan is with the Discipline of Civil Engineering, School of Engineering, Monash University Malaysia, Jalan Lagoon Selatan, 46150 Bandar Sunway Selangor Darul Ehsan, Malaysia (e-mail: andreas.aditya@monash.edu).

K. B. Tan and B. Salamatinia are with the Discipline of Chemical Engineering, School of Engineering, Monash University (e-mail: \{tan.kok.bing, babak.salamatinia\}@monash.edu). some extra precautions like inhalation of MB that will cause difficulties in breathing and ingestion through the mouth that may cause nausea, vomiting, profuse sweating, mental confusion, and methemoglobinemia [4]. Thus, it is utmost important to treat $\mathrm{MB}$ dye wastewater even at low concentrations.

One of the most common methods for dye removal at low concentration is adsorption, which is seen as a simple yet innovative way to remove dye pollutant from the effluent [5]. Currently, commercial activated carbon (CAC) has been utilized as an adsorbent to perform adsorption of dyes in wastewater because of its extraordinary property for instance large surface area, high adsorption capacity and micro porous structure. However, its use is limited due to its high regeneration and capital cost [6]-[8]. Hence, researchers are now focusing on the development of alternative new low cost adsorbents, which are more sustainable and having equivalent advantages as that of CAC.

Many low cost adsorbents have been investigated on the adsorption on MB dye. Investigation of the adsorption of $\mathrm{MB}$ using bamboo charcoal in the range of $100-500 \mathrm{mg} / \mathrm{L}$ dye initial concentration achieved percentage removal in the range of $28 \%-98 \%$ [9]. Liu et al. [10] investigated the relation between $\mathrm{pH}$ and $\mathrm{MB}$ adsorption onto kapok fiber with the $\mathrm{pH}$ ranging from 2 to 10 . At low $\mathrm{pH}$ from 2 to 6 , the adsorption was not stable and found to be fluctuating between $20 \%$ and $75 \%$, achieving highest percentage removal at optimum $\mathrm{pH}$ of 6. Yan et al. [11] also reported the effect of $\mathrm{pH}$ for MB adsorption by using carboxy-methyl cellulose as the sorbent material. It was found that the adsorption capacity increased with increasing $\mathrm{pH}$, reaching a maximum adsorption capacity of $300 \mathrm{mg} / \mathrm{L}$ at optimum $\mathrm{pH}$ of 10 . A same maximum adsorption capacity of $300 \mathrm{mg} / \mathrm{L}$ was also achieved by Bagane and Guiza using clay as an adsorbent [12].

These low-cost adsorbents show good affinity towards MB dye due to the existence of cellulose in these adsorbents, particularly carboxy-methyl cellulose. As cellulose has negative value surface charged at wide range of $\mathrm{pH}$, strong electrostatic attraction exist between it and the cationic MB dye, which leads to adsorption [10]. There is a large amount of waste paper in different forms produced daily. A lot of this cellulosic material is burned to create heat and only part of it is recycled for pulp and paper industries. Putting this fact besides the sorption ability of cellulosic material, waste paper makes a potential green source to be used as low cost adsorbent for dye removal. Pulped waste paper is introduced in this work as another potential cellulose-based low cost green adsorbent for the removal of MB. As the ability and efficiency of this material on adsorption has not been 
investigated, this work is aimed to investigate the adsorption efficiency of it on MB by varying parameters which include dye initial concentration, dye, shaker speed during batch adsorption, initial $\mathrm{pH}$, equilibrium time, dosage of adsorbent and concentration of salt for ionic strength. Besides that, this work is also aimed to obtain the optimized sets of parameters with the best maximum percentage removal of MB dye using response surface methodology.

\section{MATERIALS AND MethodOlOGY}

\section{A. Materials}

The raw material for recycled pulp is A4 toner-attached paper from Monash University Sunway Campus. For consistency of experiments $0.1 \mathrm{M}$ of $\mathrm{NaOH}$ and $\mathrm{HNO}_{3}$ were prepared for the adjustment of $\mathrm{pH}$. $\mathrm{Na}_{2} \mathrm{SO}_{3}$ is also prepared for ionic strength experiment. Methylene Blue is purchased from Sigma Aldrich, in a powder form.

\section{B. Methodology}

\section{1) Pulping process}

For pulping process, $400 \mathrm{~mL}$ of distilled water was poured inside a $1 \mathrm{~L}$ beaker, in which 2 pieces of same size waste papers obtained from print room Monash University Malaysia, were soaked for 30s. The soaked papers were then blended for 5 minutes in a commercial blender (TEFAL). After that, the pulp sample was poured into a $500 \mathrm{ml}$ beaker, whereby it was freeze dried for 24 hours using Scanvac Coolsafe freeze dryer. The dried pulp samples were then characterized using Scanning Electron Microscope (SEM) for size measurement, Zeta potential measurement for surface charge and Brunauer-Emmett-Teller (BET) for surface area.

\section{2) Adsorption process}

For the adsorption, $50 \mathrm{ml}$ of $\mathrm{MB}$ solution was prepared in Erlenmeyer flask in a known concentration. The required $\mathrm{pH}$ of the dye was adjusted using $0.1 \mathrm{M}$ of $\mathrm{NaOH}$ or $\mathrm{HNO}_{3}$. For ionic strength experiment, a desired amount of $\mathrm{Na}_{2} \mathrm{CO}_{3}$ was also added into the MB solution. A desired mass of paper pulp was then added into the MB solution, and was mixed in an orbital shaker at desired speed. At a desired time, part of the MB dye was pipetted into $1.5 \mathrm{ml}$ centrifuge tube, whereby it was centrifuged using a micro centrifuge (Labogene scanspeed mini, Denmark) at 600rpm for a minute. After that, the top part of the liquid layer was taken, the absorbance value was measured using UV-VIS Spectrophotometer (Agilent-Cary $100 \mathrm{UV}-\mathrm{Vis}$, USA), and thus the final dye concentration was obtain with correlation to absorbance value from a calibration curve prepared beforehand. The percentage removal was then calculated using the equation (1).

$$
\text { Removal percentage }(\%)=\frac{C_{i}-C_{f}}{C_{i}} \times 100 \%
$$

where, $C_{i}$ represents the initial concentration of solution, while $C_{f}$ is the final concentration of solution.

Table I shows the ranges of parameters and values defined for this experiment.

\section{3) Response surface methodology}

Response Surface Methodology (RSM) was utilized to optimize the parameters involved in the adsorption of methylene blue dye onto recycled paper pulp. The optimizations were conducted in two parts to avoid excess number of parameters in one set of design. This was performed to make sure that high number of parameters does not jeopardize the accuracy of the statistical analysis. The first part was optimized based on parameters including initial concentrations, $\mathrm{pH}$ and shaker speed. The second part was optimized including parameters time, $\mathrm{Na}_{2} \mathrm{CO}_{3}$ concentration and adsorbent dosage, with a fixed initial concentration of $5 \mathrm{ppm}$. The other three parameters were kept constant at each set of the parameters at their respective center point. 2 set of central composite design were designed using Design Expert software (StatEase 6.0.7, USA) with an $\alpha$ value $=0.5$. The actual values of each parameter at each part were based on ranges of parameters value are tabulated in Table I.

TABLE II: RANGES OF PARAMETERS VALUES

\begin{tabular}{ll}
\hline \hline Parameters & Values \\
\hline Initial Concentration & $1-10 \mathrm{ppm}$ \\
Adsorbent Dosage & $1-7 \mathrm{~g} / \mathrm{L}$ \\
Shaker Speed & $150-300 \mathrm{rpm}$ \\
Time & $1-20 \mathrm{~min}$ \\
$\mathrm{NA}_{2} \mathrm{CO}_{3}$ concentration & $0.25-1 \mathrm{~g} / \mathrm{L}$ \\
$\mathrm{pH}$ & $4-10$ \\
\hline \hline
\end{tabular}

Table III and Table IV show the sets of designs for set 1 and set 2, respectively. For each set of design, experiments were conducted at these set of parameters to investigate the percentage removal as the response. Graph of predicted response against actual response for the removal of $\mathrm{MB}$ was also generated to verify the validity of data collected. For each set of parameters a quadratic model was developed by the software and was used to predict the behavior of the system and to optimize the parameters. Experiments were also conducted at these optimized conditions, whereby the actual percentage removal was obtained and was validated in comparisons with predicted percentage removal.

TABLE III: SETS OF PARAMETERS VALUES USING RSM DEFINED BY DESIGN EXPERT FOR THE FIRST PART

\begin{tabular}{llll}
\hline \hline Run & $\boldsymbol{C}_{\boldsymbol{i}}(\mathbf{p p m})$ & Initial $\mathbf{p H}$ & $\begin{array}{l}\text { Shaker speed } \\
(\mathbf{r p m})\end{array}$ \\
\hline $\mathbf{1}$ & 1.00 & 4.00 & 150.00 \\
$\mathbf{2}$ & 10.00 & 4.00 & 150.00 \\
$\mathbf{3}$ & 1.00 & 10.00 & 150.00 \\
$\mathbf{4}$ & 10.00 & 10.00 & 150.00 \\
$\mathbf{5}$ & 1.00 & 4.00 & 300.00 \\
$\mathbf{6}$ & 10.00 & 4.00 & 300.00 \\
$\mathbf{7}$ & 1.00 & 10.00 & 300.00 \\
$\mathbf{8}$ & 10.00 & 10.00 & 300.00 \\
$\mathbf{9}$ & 3.25 & 7.00 & 225.00 \\
$\mathbf{1 0}$ & 7.75 & 7.00 & 225.00 \\
$\mathbf{1 1}$ & 5.50 & 5.50 & 225.00 \\
$\mathbf{1 2}$ & 5.50 & 8.50 & 225.00 \\
$\mathbf{1 3}$ & 5.50 & 7.00 & 187.50 \\
$\mathbf{1 4}$ & 5.50 & 7.00 & 262.50 \\
$\mathbf{1 5}$ & 5.50 & 7.00 & 225.00 \\
$\mathbf{1 6}$ & 5.50 & 7.00 & 225.00 \\
$\mathbf{1 7}$ & 5.50 & 7.00 & 225.00 \\
$\mathbf{1 8}$ & 5.50 & 7.00 & 225.00 \\
$\mathbf{1 9}$ & 5.50 & 7.00 & 225.00 \\
$\mathbf{2 0}$ & 5.50 & 7.00 & 225.00 \\
\hline \hline
\end{tabular}




\section{RESULTS AND DISCUSSIONS}

\section{A. Characterization}

\section{1) SEM-imaging}

Fig. 1 shows the SEM image of recycled pulp produced after being freeze dryed. Fine fibrous tape-shaped structures, which did not agglomerate were observed. This is because sublimation process takes place due to the low pressure vacuumed by the pump and low temperature from the freezer, and therefore the gas-solid phase of water is achieved.

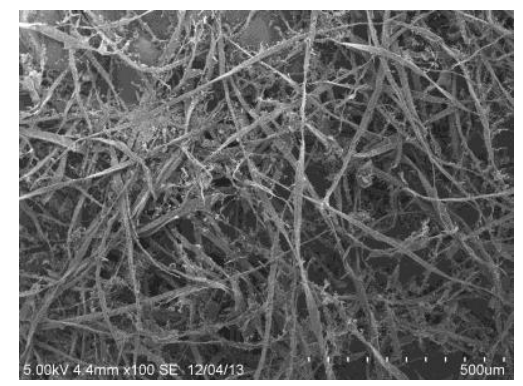

Fig. 1. SEM Imaging after Freeze drying.

TABLE IV: SETS OF PARAMETERS VALUES USING RSM DEFINED BY DESIGN EXPERT FOR THE SECOND PART

\begin{tabular}{cccc}
\hline Run & $\begin{array}{c}\text { Time } \\
(\mathbf{m i n})\end{array}$ & $\begin{array}{c}\text { Adsorbent } \\
\text { dosage }(\mathbf{g} / \mathbf{L})\end{array}$ & $\begin{array}{c}\mathbf{C} \text { of } \mathbf{N a}_{\mathbf{2}} \mathbf{C O}_{\mathbf{3}} \\
(\mathbf{g} / \mathbf{L})\end{array}$ \\
\hline $\mathbf{1}$ & 1 & 1 & 0 \\
$\mathbf{2}$ & 20 & 1 & 0 \\
$\mathbf{3}$ & 1 & 7 & 0 \\
$\mathbf{4}$ & 20 & 7 & 0 \\
$\mathbf{5}$ & 1 & 1 & 1 \\
$\mathbf{6}$ & 20 & 1 & 1 \\
$\mathbf{7}$ & 1 & 7 & 1 \\
$\mathbf{8}$ & 20 & 7 & 1 \\
$\mathbf{9}$ & 5.75 & 4 & 0.5 \\
$\mathbf{1 0}$ & 15.25 & 4 & 0.5 \\
$\mathbf{1 1}$ & 10.5 & 2.5 & 0.5 \\
$\mathbf{1 2}$ & 10.5 & 5.5 & 0.5 \\
$\mathbf{1 3}$ & 10.5 & 4 & 0.25 \\
$\mathbf{1 4}$ & 10.5 & 4 & 0.75 \\
$\mathbf{1 5}$ & 10.5 & 4 & 0.5 \\
$\mathbf{1 6}$ & 10.5 & 4 & 0.5 \\
$\mathbf{1 7}$ & 10.5 & 4 & 0.5 \\
$\mathbf{1 8}$ & 10.5 & 4 & 0.5 \\
$\mathbf{1 9}$ & 10.5 & 4 & 0.5 \\
$\mathbf{2 0}$ & 10.5 & 4 & 0.5 \\
\hline \hline
\end{tabular}

The range of temperature and pressure where gas-solid phase occurs is between 0 to $-130^{\circ} \mathrm{C}$ and also at any pressure less than $1 \mathrm{kPa}$ [13], which can be achieved through freeze dryer with vacuum pump. Thus, the pulp generated will not agglomerate to each other leading to a higher surface area and therefore a better chance of adsorption.

The smallest pulp fiber diameter obtained in this experiment was $5.75 \mathrm{~mm}$. In comparison with study done by Chandra et al. [14], smaller particle size can be achieved by using different material such as bamboo with $2.7 \mathrm{~mm}$ or cotton stalks with $0.8 \mathrm{~mm}$ in size. The reason why recycled paper pulp will give bigger size is because of the compactness structure of the fiber during the paper making process. It has already been compressed and therefore it tends to stick to each other in comparison with natural cotton stalk or bamboo.

\section{2) Zeta potential testing}

Zeta potential test for the fresh pulp before adsorption at different points of $\mathrm{pH}$ was carried out. From the graph shown in Fig. 2, the most negative charge will happen in $\mathrm{pH}$ between
5.5 and 7. A significant drop in zeta potential could be seen from $\mathrm{pH} 4$ to $\mathrm{pH} 5.5$ due to the occurrence of deprotonation. However, at $\mathrm{pH}$ around 5.5 to 7 , the zeta potential value shifted towards positive charges due to the excessive hydroxyl group present. As comparative study with literature review, Yan et al. [11] reported that the zeta potential would only go towards positive charges starting at $\mathrm{pH} 10$ with carboxymethyl cellulose as adsorbent. The reason why recycle paper pulp had different turning point is probably due to the extreme negative charge caused by the carboxyl group on CMC [15]. Also the difference could be attributed to the presence of some chemicals during the paper making process and also the ink and tuner present on waste paper. Major basic chemicals used during paper production are Alkylphenol Ethoxylates and sodium hydroxide [16]. With the present of these chemicals even in only small amount, it will affect the turning point for the zeta potential of paper pulp. Therefore, it was expected to have the best methylene blue removal at $\mathrm{pH}$ between 5.5 and 7 as the most negative charged which is $-16.2 \mathrm{mV}$ is achieved in this range of $\mathrm{pH}$.

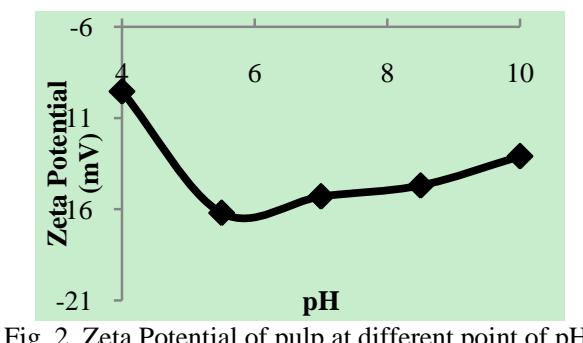

Fig. 2. Zeta Potential of pulp at different point of $\mathrm{pH}$

\section{3) BET test-surface area}

BET was conducted to measure the surface area of the paper pulp. The result showed that the surface area of paper pulp is fairly low, which is $1.15 \mathrm{~m}^{2} / \mathrm{g}$. The low surface obtained was mostly due to the large size of the adsorbent, which in turn will limit the surface contact area. In comparison with literature study, the average surface area for efficient adsorbent is approximately $200 \mathrm{~m}^{2} / \mathrm{g}$. However, even though pulp has very small surface area, it will still be used as the adsorbent for methylene blue to be analyzed further.

TABLE V: RESUlts OBTAINED USING DEFINED SETS OF PARAMETERS

\begin{tabular}{lllll}
\hline \hline Run & $\begin{array}{l}\boldsymbol{C}_{\boldsymbol{i}} \\
(\mathbf{p p m})\end{array}$ & $\begin{array}{l}\text { Initial } \\
\mathbf{p H}\end{array}$ & $\begin{array}{l}\text { Shaker speed } \\
(\mathbf{r p m})\end{array}$ & $\begin{array}{l}\text { Removal } \\
\text { Percentage }(\boldsymbol{\%})\end{array}$ \\
\hline $\mathbf{1}$ & 1.00 & 4.00 & 150.00 & 65.00 \\
$\mathbf{2}$ & 10.00 & 4.00 & 150.00 & 71.52 \\
$\mathbf{3}$ & 1.00 & 10.00 & 150.00 & 47.15 \\
$\mathbf{4}$ & 10.00 & 10.00 & 150.00 & 61.43 \\
$\mathbf{5}$ & 1.00 & 4.00 & 300.00 & 81.47 \\
$\mathbf{6}$ & 10.00 & 4.00 & 300.00 & 94.99 \\
$\mathbf{7}$ & 1.00 & 10.00 & 300.00 & 83.53 \\
$\mathbf{8}$ & 10.00 & 10.00 & 300.00 & 93.48 \\
$\mathbf{9}$ & 3.25 & 7.00 & 225.00 & 85.01 \\
$\mathbf{1 0}$ & 7.75 & 7.00 & 225.00 & 87.96 \\
$\mathbf{1 1}$ & 5.50 & 5.50 & 225.00 & 81.91 \\
$\mathbf{1 2}$ & 5.50 & 8.50 & 225.00 & 79.41 \\
$\mathbf{1 3}$ & 5.50 & 7.00 & 187.50 & 77.16 \\
$\mathbf{1 4}$ & 5.50 & 7.00 & 262.50 & 87.27 \\
$\mathbf{1 5}$ & 5.50 & 7.00 & 225.00 & 83.40 \\
$\mathbf{1 6}$ & 5.50 & 7.00 & 225.00 & 87.40 \\
$\mathbf{1 7}$ & 5.50 & 7.00 & 225.00 & 86.27 \\
$\mathbf{1 8}$ & 5.50 & 7.00 & 225.00 & 84.28 \\
$\mathbf{1 9}$ & 5.50 & 7.00 & 225.00 & 83.65 \\
$\mathbf{2 0}$ & 5.50 & 7.00 & 225.00 & 85.27 \\
\hline \hline
\end{tabular}




\section{B. Adsorption of Methylene Blue (Set 1)}

Table V shows the results obtained using first defined set of parameters designed. An equation to predict the removal percentage of methylene blue based on the first set of parameters ranging as specified above is presented in equation (2) where, $\mathrm{A}$ is defined as initial concentration, in $\mathrm{ppm}$. $\mathrm{B}$ is $\mathrm{pH}$, while $\mathrm{C}$ is shaker speed, in rpm. If the response is well modeled by a linear function of the independent variables, then the approximating function is a first-order model. If there is a curvature in the system or in the region of the optimum, then a polynomial of higher degree is employed tin order to predict the response. This developed model is used to analyze and locate the optimum conditions based on the set of independent variables in a way that the partial derivative of the model response with respect to the individual independent variables is equal to zero. The ultimate goal of RSM is to find out the optimum operating conditions for the system, or to establish the region, which more suits the operating specifications [17]. Almost all RSM problems utilize one or both of these approximating polynomials [18]. In the analysis of variance (INNOVA) performed by the software the non-significant terms were removed from the model. The significance of the parameters was performed with statistical Prob. $>F$. Initially; there were two non-significant relation terms in the analysis of the software, which were removed from the model. The second order relationship between initial concentration and initial $\mathrm{pH}$ was removed as well as the second order interaction between initial concentration and shaker speed to increase the significance of the graph. By removing the unrelated variables, the standard deviation of error was reduced from 2.03 to 1.92 , with a high coefficient of correlation (R-squared) of 0.982 with an average removal percentage of $80.38 \%$. An equation to predict the removal percentage of methylene blue based on the parameters ranging as specified in the scope shown in equation (2) where $\mathrm{A}$ is defined as initial concentration, in ppm. $\mathrm{B}$ is $\mathrm{pH}$, while $\mathrm{C}$ is shaker speed, in rpm.

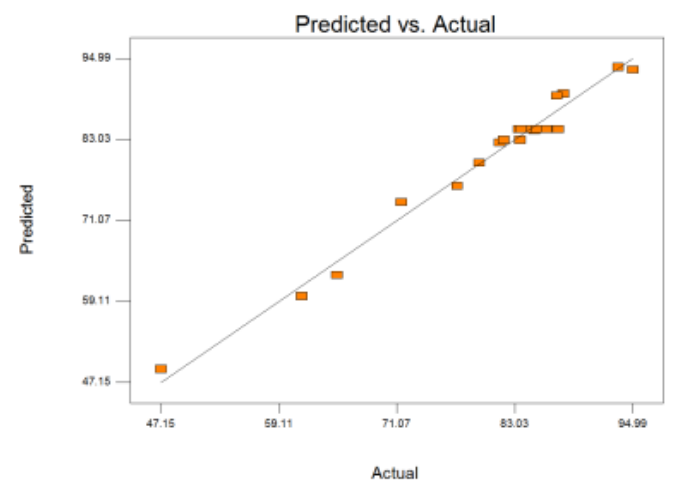

Fig. 3. Predicted vs Actual removal percentage of MB.

A graph of actual vs. predicted was plotted using the software to check the complying of the experimental data with the model generated and is presented in

Fig. 3, the predicted percentage removal does comply with the actual removal from experiment.

Removal Percentage $(\%)=-46.95-4.35 A+15.67 B+$ $0.61 C+0.50 A^{2}-1.45 B^{2}-1.22 .10^{-3} C^{2}+$

$0.02 B C$

\section{1) Effect of initial concentration and ph on percentage removal}

The changes in initial concentration and initial $\mathrm{pH}$ will affect the removal percentage of methylene blue. To observe the interaction between these two parameters, a 3D graph is plotted as shown in Fig. 4 with constant shaker speed of 200 rpm. The effect of initial concentration towards removal percentage can be seen where the removal percentage tends to drop between 1 and $5 \mathrm{ppm}$. However, even though the removal percentage is lower, it will still give higher adsorption capacity. This is due to the presence of unoccupied sites of adsorbent during the experiment at lower concentration, which will still be able to take dye pigment when concentration is gone up. At the other hand, at concentration varied from 5 to $10 \mathrm{ppm}$, it behaves differently as the removal percentage goes up again with the increment of adsorption capacity as well. As dosage is maintained at constant $4 \mathrm{~g} / \mathrm{L}$ and the reaction time is also fixed at 10 minutes, it is possible to see the instability of pulp characteristic as the adsorbent for the range of low concentration. as a comparative study done by Karima et al. [19], when clay is used as the adsorbent, the removal of methylene blue is yet unstable at very low concentration range, which is from 1 to $20 \mathrm{ppm}$. In order to obtain the stability of adsorption, reaction time should be put longer about 30 to 40 minutes.

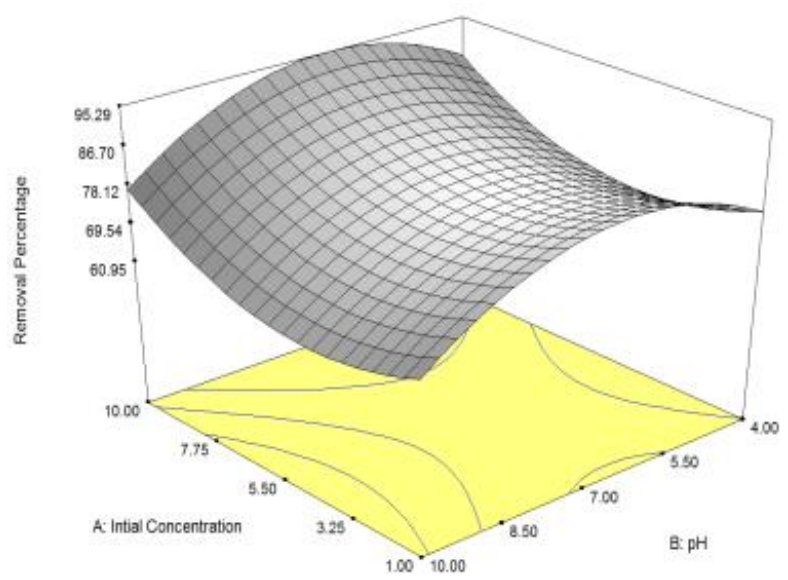

Fig. 4. 3D Correlation between initial concentration and initial $\mathrm{pH}$ for methylene blue removal percentage while shaker speed was kept constant at the center level of $225 \mathrm{rpm}$.

From Fig. 4, effect of $\mathrm{pH}$ to the removal percentage of methylene blue can be observed as well. An upward curve pattern can be seen from the range of the $\mathrm{pH}$. This correlation complies with the zeta potential testing for different $\mathrm{pH}$ of adsorbent where the most negative charge adsorbent will be obtained at $\mathrm{pH}$ ranged from 5.5 to 7 . As the negative charge increases, the removal of methylene blue will increase as well. In combination between initial concentration and initial $\mathrm{pH}$, maximum removal percentage can go up to $95.29 \%$, where the initial concentration is set at $10 \mathrm{ppm}$ and initial $\mathrm{pH}$ 7. Adsorption capacity was calculated and found to be 1.31 $\mathrm{mg} \mathrm{MB/g} \mathrm{pulp.}$

This is considered a low adsorption capacity in comparison with activated carbon that has more than $200 \mathrm{mg} \mathrm{MB} / \mathrm{g}$ adsorption capacity [4]. However, comparing the cost of the waste paper to activated carbon makes this sorbent a potentially favorable material for sorption process. 


\section{2) Effect of initial concentration and shaker speed on percentage removal}

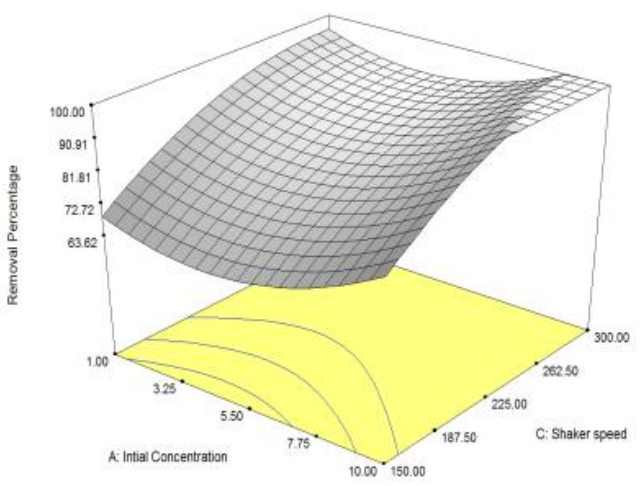

Fig. 5. 3D relation between initial concentration and shaker speed when $\mathrm{pH}$ was kept at its center level of 7

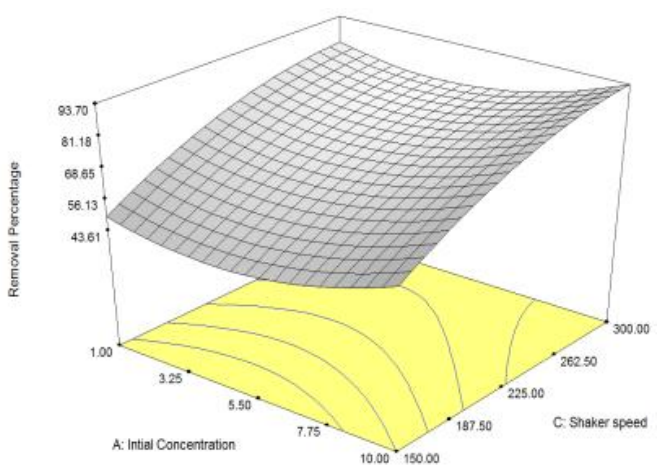

Fig. 6. 3D relation between initial concentration and shaker speed when $\mathrm{pH}$ was kept at its center level of 10 .

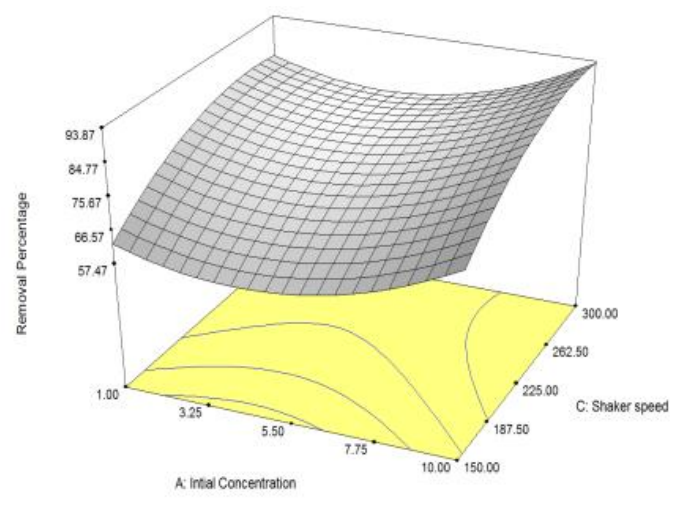

Fig. 7. 3D relation between initial concentration and shaker speed when $\mathrm{pH}$ was kept at its center level of 4 .

Fig. 5, Fig. 6 and Fig. 7 show the 3D relation between initial concentration, shaker speed, by varying the $\mathrm{pH}$ at its central, highest and lowest range, respectively. As could be noted the variation in the $\mathrm{pH}$ does change the trend of the interaction between the 2 other parameters. The increasing of shaker speed will improve the removal of methylene blue due to a better contact between the dye molecules and the adsorbent. This will eventually lead to a faster equilibrium time, and oppositely when shaker speed is reduced, longer time is required in order for the adsorption to reach equilibrium. The unique point of the relation come at $\mathrm{pH} 7$ as shown in Fig. 5 where there was a white layer plotted in the Design Expert Software. This white layer represented the removal percentage predicted that went higher than $100 \%$ by the interpolation of the software. This is considered as the error by the software and further study should be done in order to minimize the error. The reason to this error is that the RSM software only relies on values to make the predication and a certain level of error in the prediction is unavoidable. Other than that, the three graphs showed high reliability of paper pulp as adsorbent on these parameters, which is confirmed by the wide range of methylene blue removal from as low as $43 \%$ to as high as $99 \%$. Maximum adsorption capacity that can be achieved in this correlation is found to be $2.5 \mathrm{mg} / \mathrm{g}$. With different variables being observed, it was still concluded that paper pulp even though can show high rate adsorption for methylene blue dye, yet since the sorption capacity is low large amount of waste paper might be required for the same amount of removal as compared to other commercial sorbents.

\section{3) Optimization of methylene blue adsorption for set 1}

Optimization of the adsorption process was carried out using response surface methodology. By using numerical optimization process, each of the parameters was set to obtain the highest removal percentage as possible. Table VI shows the configuration of each variable, where the three parameters involved in the study are all set in range, and the removal percentage is set at maximum level. Sets of parameter values were then produced with the expected removal percentage. In order to confirm the validity of the model those 3 set points were tested and error was calculated by the difference between predicted and experimental outcome. The result of the optimization is shown in Table VII. Since the error from the experimental and predicted value is not significant $(<5 \%)$, it could be concluded that the response surface methodology approach was valid.

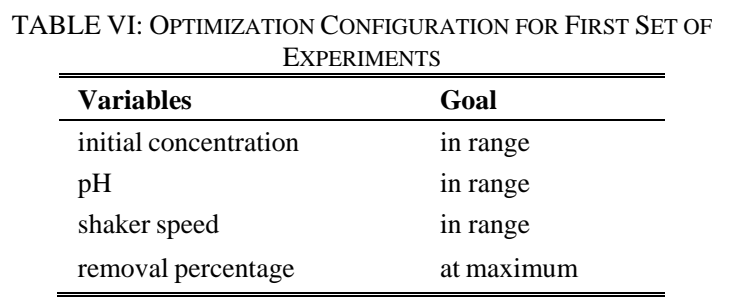

TABLE VII: OPTIMIZATION RESULT FOR SET 1 OF DESIGN AND THE ERRORS Calculated Between PRedict vs. Actual

\begin{tabular}{cccccc}
\hline \hline $\begin{array}{c}\boldsymbol{C}_{\boldsymbol{i}} \\
(\mathbf{p p m})\end{array}$ & $\mathbf{p H}$ & $\begin{array}{c}\text { Shaker } \\
\text { speed (rpm) }\end{array}$ & $\begin{array}{c}\text { Predicted } \\
(\boldsymbol{\%})\end{array}$ & $\begin{array}{c}\text { Actual } \\
(\boldsymbol{\%})\end{array}$ & $\begin{array}{c}\mathbf{E} \\
(\boldsymbol{\%})\end{array}$ \\
\hline 1 & 6.5 & 300 & 95.34 & 91.60 & 3.74 \\
9.5 & 5.6 & 230 & 97.08 & 95.24 & 1.84 \\
8 & 5.9 & 280 & 95.29 & 95.11 & 0.18 \\
\hline \hline
\end{tabular}

\section{Adsorption of Methylene Blue (Set 2)}

In Second part, the effect of reaction time, adsorbent dosage and ionic strength were investigated, with dye initial concentration of $5 \mathrm{ppm}$ which is the average of the dye concentration in this experiment. Table VIII shows the results obtained from the defined set of these parameters. The following quadratic regression model was generated to predict the behavior of set 2 parameters using RSM.

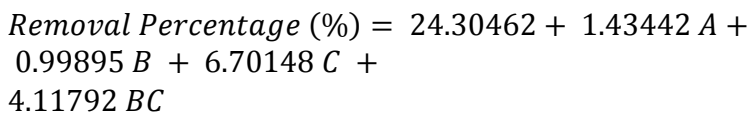

In (3), A represents the reaction time, $\mathrm{B}$ represents the dosage of adsorbent and $\mathrm{C}$ represents the concentration of 
sodium carbonate.

It was important to ignore the insignificant interaction between variables having 'Prob $>F$ ' less than 0.05 [20]. Hence, term A2, B2, C2, AB and AC were removed due to their high 'Prob $>F$ ' value higher than 0.05 . In other words, these terms are not effective in analyzing the percentage of dye removal. Besides, the predicted against actual responses was plotted by the software and it can be seen in Fig. 8. The predicted values are calculated from RSM while the actual values are measured from the experiment. It was observed that the correlation coefficient $\left(\mathrm{R}^{2}\right)$ value is relatively high at 0.9621 . This pictures the reliability of the model fitting the experimental data at a high level of confidence.

TABLE VIII : RESULTS FOR DEFINED SETS OF PARAMETERS

\begin{tabular}{ccccc}
\hline \hline Run & $\begin{array}{c}\text { Duration } \\
(\mathbf{m i n})\end{array}$ & $\begin{array}{c}\text { Dosage } \\
(\mathbf{g} / \mathbf{L})\end{array}$ & $\begin{array}{c}\mathbf{C}_{\text {Na2CO3 }} \\
(\mathbf{g} / \mathbf{L})\end{array}$ & $\begin{array}{c}\text { Removal } \\
\text { percentage }(\%)\end{array}$ \\
\hline $\mathbf{1}$ & 1 & 1 & 0 & 9.02 \\
$\mathbf{2}$ & 20 & 1 & 0 & 34.20 \\
$\mathbf{3}$ & 1 & 7 & 0 & 14.66 \\
$\mathbf{4}$ & 20 & 7 & 0 & 41.64 \\
$\mathbf{5}$ & 1 & 1 & 1 & 20.58 \\
$\mathbf{6}$ & 20 & 1 & 1 & 45.91 \\
$\mathbf{7}$ & 1 & 7 & 1 & 47.28 \\
$\mathbf{8}$ & 20 & 7 & 1 & 81.69 \\
$\mathbf{9}$ & 5.75 & 4 & 0.5 & 63.94 \\
$\mathbf{1 0}$ & 15.25 & 4 & 0.5 & 71.78 \\
$\mathbf{1 1}$ & 10.5 & 2.5 & 0.5 & 65.73 \\
$\mathbf{1 2}$ & 10.5 & 5.5 & 0.5 & 70.54 \\
$\mathbf{1 3}$ & 10.5 & 4 & 0.25 & 72.33 \\
$\mathbf{1 4}$ & 10.5 & 4 & 0.75 & 77.42 \\
$\mathbf{1 5}$ & 10.5 & 4 & 0.5 & 65.31 \\
$\mathbf{1 6}$ & 10.5 & 4 & 0.5 & 63.39 \\
$\mathbf{1 7}$ & 10.5 & 4 & 0.5 & 62.70 \\
$\mathbf{1 8}$ & 10.5 & 4 & 0.5 & 62.15 \\
$\mathbf{1 9}$ & 10.5 & 4 & 0.5 & 63.80 \\
$\mathbf{2 0}$ & 10.5 & 4 & 0.5 & 64.90 \\
\hline \hline
\end{tabular}

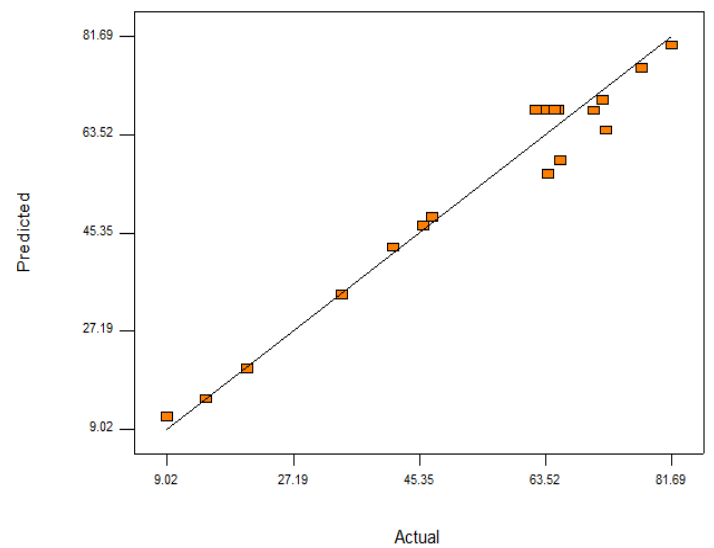

Fig. 8. Predicted vs Actual removal percentage of MB.

\section{1) Effect of ionic strength and reaction time on percentage removal}

To study the effect of ionic strength on the percentage of dye removal, sodium carbonate which is an ionic compound was varied between $0 \mathrm{~g} / \mathrm{L}$ to $1 \mathrm{~g} / \mathrm{L}$. Theoretically, Al-Degs et al. highlighted that when the adsorbent and dye are of opposite charges, the adsorption is expected to decrease with the increase in ionic strength [2]. However, the experiment conducted did not comply with this theory, although methylene blue and waste paper are of the opposite charges. Instead, the percentage of dye removal increases with the concentration of sodium carbonate at all times as shown in Fig. 9. For instance, at a reaction time of 1 minute, the percentage of dye removal increases from $31.84 \%$ to $53.12 \%$ when the concentration of sodium carbonate increases from 0 $\mathrm{g} / \mathrm{L}$ to $1 \mathrm{~g} / \mathrm{L}$. This increase was explained by the same researchers where it was concluded that the repulsion force between dye molecules can be reduced when salt is added and therefore this can lead to higher sorption possibilities With the aggregation of methylene blue dye molecules caused by the salt ions, the extent of adsorption on the surface of waste paper can be increased [2]. Hence, higher ionic strength in the solution caused better aggregation of dye molecules which will then lead to higher percentage of dye removal.

\section{2) Effect of adsorbent dosage and reaction time on percentage removal}

To study the effect of reaction time on the percentage of dye removal, the reaction time was varied from 1 minute to 20 minutes. As shown in Fig. 10, it can be seen that at any adsorbent dosage, the percentage of dye removal increases with reaction time and after a certain period of reaction time, the percentage of dye removal will decrease with reaction time. For instance, with adsorbent dosage of $1 \mathrm{~g} / \mathrm{L}$, the percentage of dye removal will increase from $7.68 \%$ to $41.92 \%$ when reaction time increases from 1 minute to 14 minutes. However, the percentage of dye removal decreases from $41.92 \%$ to $32.22 \%$ when the reaction time increases from 14 minutes to 20 minutes. According to Dutta et al. [8], a longer reaction time will allow the dye molecule to have more time to find an active site on the adsorbent.

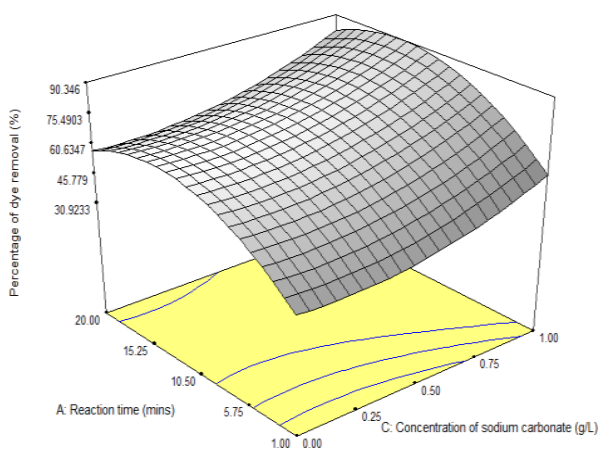

Fig. 9. 3D Correlation between percentage of dye removal with reaction time and concentration of sodium carbonate at constant dosage of adsorbent of 4 $\mathrm{g} / \mathrm{L}$.

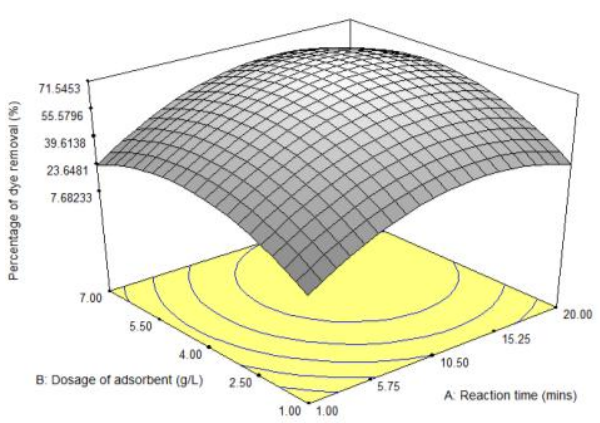

Fig. 10. 3D Correlation between percentage of dye removal with dosage of adsorbent and reaction time at constant concentration of sodium carbonate at $0.5 \mathrm{~g} / \mathrm{L}$.

Hence, the percentage of dye removal will increase with reaction time. Nonetheless, it was found that after a certain 
period of reaction time, the adsorbent is fully saturated causing the surrounding environment to have a lower concentration of dye. This difference in concentration will cause a mass transfer where the dye molecule will move from a higher concentration region to a lower concentration region which describes the desorption process [8]. Therefore, this explains why the percentage of dye removal decreases with reaction time after a certain period of reaction time.

3) Effect of adsorbent dosage and ionic strength on percentage removal

To study the effect of adsorbent dosage on the percentage of dye removal, the dosage was varied from $1 \mathrm{~g} / \mathrm{L}$ to $7 \mathrm{~g} / \mathrm{L}$. As shown in Fig. 11, at any concentration of sodium carbonate, the percentage of dye removal increases with adsorbent dosage and after a certain amount of dosage, the percentage of dye removal decreases with adsorbent dosage. For instance, at $1 \mathrm{~g} / \mathrm{L}$ of sodium carbonate, the percentage of dye removal increases from $53.44 \%$ to $90.61 \%$ as the dosage of adsorbent increases from $1 \mathrm{~g} / \mathrm{L}$ to $5 \mathrm{~g} / \mathrm{L}$. However, the percentage of dye removal decreases from $90.61 \%$ to $84.14 \%$ as the adsorbent of dosage increases from $5 \mathrm{~g} / \mathrm{L}$ to $7 \mathrm{~g} / \mathrm{L}$.

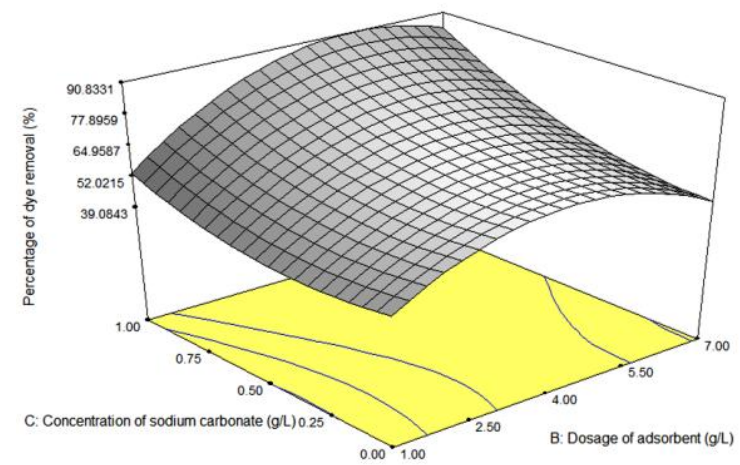

Fig. 11. 3D Correlation between percentage of dye removal with concentration of sodium carbonate and dosage of adsorbent at constant reaction time of 10.5 minutes.

According to a study done by Dutta et al. [8], the percentage of dye removal will increase with dosage of adsorbent due to the much more active site for the dye molecule to attach on. Nonetheless, there is a decrease in the percentage of dye removal after a certain amount of adsorbent dosage because at higher dosage of adsorbent, the particles that made up the adsorbent may overlap each other and hence blocking some active sites for the dye molecule to attach on [8]. Therefore, this explains the decrease in dye removal percentage at higher amount of adsorbent.

\section{4) Process optimization (Set 2)}

The Response Surface Methodology was utilized to further optimize the independent variables. It was desired to achieve the highest percentage of dye removal within the specified range of reaction time, dosage of adsorbent as well as concentration of sodium carbonate. Table IX shows the optimized values of respective independent variable with the predicted percentage of dye removal calculated via RSM, experimental percentage of dye removal and percentage of error for each set of experiment. The errors calculated in Table IX were mainly due to error occurred during the experiment. For instance, run 1 requires $4.71 \mathrm{~g} / \mathrm{L}$ dosage of adsorbent. However, it was difficult to measure the amount of adsorbent precisely at $4.71 \mathrm{~g} / \mathrm{L}$ and hence an approximated value was taken. In addition, according to any percentage error under $5 \%$ is acceptable. Therefore, the errors calculated in Table IX are acceptable and it also verifies the reliability of RSM to optimize the independent variables involved in this study.

TABLE IX: OPTIMIZATION RESULT FOR SET 1 OF DESIGN AND THE ERRORS CALCUlated BETWEEN PREDICT VS. ACTUAL

\begin{tabular}{cccccc}
\hline $\begin{array}{c}\text { Time } \\
(\mathbf{m i n})\end{array}$ & $\begin{array}{c}\text { Adsorbent } \\
\text { Dosage } \\
(\mathbf{g} / \mathbf{L})\end{array}$ & $\begin{array}{c}\mathbf{N a}_{\mathbf{2}} \mathbf{C O}_{\mathbf{3}} \\
\mathbf{C o n c e n} \\
(\mathbf{g} / \mathbf{L})\end{array}$ & $\begin{array}{c}\text { Actual } \\
(\boldsymbol{\%})\end{array}$ & $\begin{array}{c}\text { Predicted } \\
(\boldsymbol{\%})\end{array}$ & $\begin{array}{c}\mathbf{E} \\
(\boldsymbol{\%})\end{array}$ \\
\hline 9.37 & 4.71 & 0.88 & 83.04 & 81.89 & 1.404 \\
13.74 & 4.67 & 0.82 & 84.76 & 83.33 & 1.716 \\
13.05 & 5.98 & 0.94 & 89.30 & 88.50 & 0.904 \\
\hline
\end{tabular}

5) Equilibrium study

An equilibrium study was performed to investigate the equilibrium concentration and equilibrium time for methylene blue dye at 1,3,5,7 and 9 ppm. In this study, a system was said to have achieved equilibrium when the final concentration of dye is almost constant with time. At this point of time, the number of dye molecules adsorbed is equal to the number of dye molecules desorbed [20]. On the other hand, a graph of final concentration of methylene blue dye against time for various initial concentration of dye was plotted to show the equilibrium curve as presented in

Fig. 12. It was observed that the equilibrium concentration and equilibrium time increases with the concentration of methylene blue dye. The equilibrium curve for methylene blue at $1 \mathrm{ppm}$ has a horizontal line due to the low dye concentration compared to the other four equilibrium curves, which were done at a higher dye concentration.

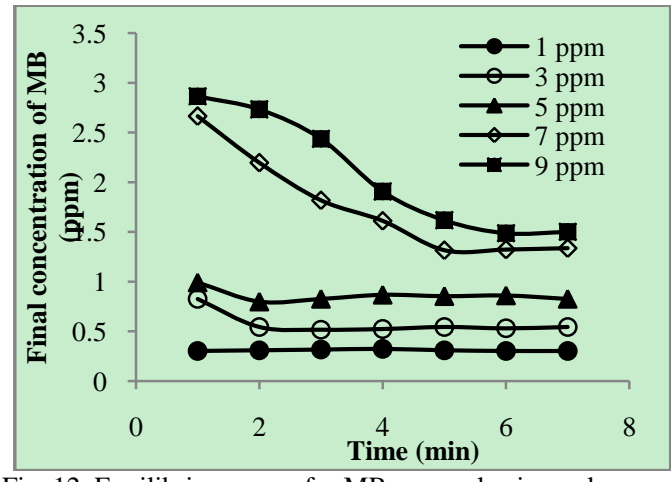

Fig. 12. Equilibrium curve for MB removal using pulp paper.

TABLE X: RESPECTIVE EQUILIBRIUM TIME AND EQUILIBRIUM CONCENTRATION FOR VARIOUS CONCENTRATION OF METHYLENE BLUE

\begin{tabular}{|c|c|c|}
\hline $\begin{array}{l}\text { Concentration of } \\
\text { MB dye (ppm) }\end{array}$ & $\begin{array}{l}\text { Equilibrium } \\
\text { time, } T_{e}(\min )\end{array}$ & $\begin{array}{c}\text { Equilibrium } \\
\text { concentration, } C_{e}(\mathrm{ppm})\end{array}$ \\
\hline 1 & 1 & 0.303 \\
\hline 3 & 2 & 0.544 \\
\hline 5 & 3 & 0.826 \\
\hline 7 & 5 & 1.315 \\
\hline 9 & 6 & 1.487 \\
\hline
\end{tabular}

At such low concentration, with same amount of adsorbent, the concentration will decrease rapidly compared to those that are of high concentration. Hence, it was difficult to measure the equilibrium concentration and time for low concentration of dye. Table $\mathrm{X}$ shows the equilibrium concentration and equilibrium time for respective dye concentration.

According to [19], equilibrium time for low concentration of methylene blue is 7-10 minutes. The experimental study 
showed a similar trend where 7 minutes the maximum equilibrium time at $9 \mathrm{ppm}$ concentration of $\mathrm{MB}$ was. However, at higher concentration of methylene blue such as $100 \mathrm{ppm}$, the equilibrium time can jump up to 3 hours.

\section{CONCLUSION}

Due to the demand for sustainable process in engineering fields, the usage of paper pulp as adsorbent for MB removal in waste water could be considered as an option. Though papers do not have a large surface area, the ability to absorb MB in low concentration is proven to be feasible. With further research for isotherm study and testing at high concentration of pollutant, waste papers could be great idea for sustainability idea compared with conventional method such as using commercial activated carbon.

\section{ACKNOWLEDGEMENT}

The Authors of this work highly acknowledge School of Engineering, Monash University Malaysia for the endless support. Also Ms. Adeline Saw Phaik Joo who has helped a lot in having this research done during her final year project.

\section{REFERENCES}

[1] S. C. Druding. (May 25, 2012). Dye History from $2600 \mathrm{BC}$ to the 20th Century. [Online]. Available: http://www.straw.com/sig/dyehist.html

[2] Y. S. Al-Degs, M. I. El-Barghouthi, A. H. El-Sheikh, and G. M. Walker, "Effect of solution $\mathrm{pH}$, ionic strength, and temperature on adsorption behavior of reactive dyes on activated carbon," Dyes and Pigments, vol. 77, pp. 16-23, 2008.

[3] C. Deng, J. Liu, W. Zhou, Y.-K. Zhang, K.-F. Du, and Z.-M. Zhao, "Fabrication of spherical cellulose/carbon tubes hybrid adsorbent anchored with welan gum polysaccharide and its potential in adsorbing methylene blue," Chemical Engineering Journal, pp. 452-458, 2012.

[4] M. Rafatullah, O. Sulaiman, R. Hashim, and A. Ahmad, "Adsorption of methylene blue on low-cost adsorbents: A review," Journal of Hazardous Materials, pp. 70-80, 2010.

[5] N. B. Douissa, L. Bergaoui, S. Mansouri, R. Khiari, and M. F. Mhenni, "Macroscopic and microscopic studies of methylene blue sorption onto extracted celluloses from Posidonia oceanica," Industrical Crops and Products, pp. 106-113, 2013.

[6] A. Jain, V. Gupta, and A. Bhatnagar, "Utilization of industrial waste products as adsorbents for the removal of dyes," Journal of Hazardous Materials, vol. 101, pp. 31-42, 2003.

[7] P. K. Malik, "Use of activated carbons prepared from sawdust and rice-husk for adsorption of acid dyes: A case study of acid yellow 36," Dyes and Pigments, vol. 56, pp. 239-249, 2003.

[8] S. Dutta, A. Bhattacharyya, A. Ganguly, S. Gupta, and S. Basu, "Application of response surface methodology for preparation of low-cost adsorbent from citrus fruit peel and for removal of methylene blue," Desalination, vol. 275, pp. 26-36, 2011.

[9] Y. Zhu, D. Wang, X. Zhang, and H. Qin, "Adsorption removal of methylene blue from aqueous solution by using bamboo charcoal," Fresenius Environmental Bulletin, vol. 18, pp. 1-8, 2009.

[10] Y. Liu, J. Want, Y. Zheng, and A. Wang, "Adsorption of methylene blue by kapok fiber treated by sodium chlorite optimized with response surface methodology," Chemical Engineering Journal, vol. 184, pp. 248-255, 2012.

[11] H. Yan, W. Zhang, X. Kan, L. Dong, Z. Jiang, H. Li, H. Yang, and R. Cheng, "Sorption of methylene blue by carboxymethyl cellulose and reuse process in a secondary sorption," Colloids and Surfaces A, vol. 380, pp. 143-151, 2011.

[12] M. Bagane and S. Guiza, "Reactivity and reaction Kinetics-Removal of a dye from textile effluents by adsorption," Annales de Chimie-Science des Materiaux, pp. 615-626, 2000.

[13] P. L. Garrido. (2013). Water structure and behavior, The phase diagram of water. [Online]. Available: http://ergodic.ugr.es/termo/lecciones/water1.html
[14] M. Chandra, Use of Nonwood Plant Fibers for Pulp and Paper Industry in Asia: Potential in China, Virginia Polytechnic Institute and State University, 1998, pp. 1-24.

[15] L. L. Shao, Q. F. An, Y. L. Ji, Q. Zhao, X. S. Wang, B. K. Zhu, and C. J. Gao, "Preparation and characterization of sulfated carboxymethyl cellulose nanofiltration membranes with improved water permeability," Desalination, vol. 338, pp. 74-83, 2014.

[16] Paperonweb. (June 1, 2010). Chemicals used in pulp \&paper manufacturing and coating. [Online]. Available: www.paperonweb.com/chemical.htm

[17] A. Z. Abdullah, B. Salamatinia, and A. H. Kamaruddin, "Application of response surface methodology for the optimization of $\mathrm{NaOH}$ treatment on oil palm frond towards improvement in the sorption of heavy metals," Desalination, vol. 244, pp. 227-238, 2009.

[18] A. I. Khuri and J. A. Cornell, Response Surfaces: Design and Analyses, New York: Marcel Dekker, 1996

[19] B. Karima, B. L. Mossab, and M. A-Hassen, "Removal of methylene blue from aqueous solutions using an acid activated algerian bentonite: Equilibrium and kinetic studies," International Renewable Energy Congress, pp. 1-8, 2010.

[20] Y. Chen, "Synthesis, characterization and dye adsorption of ilmenite nanoparticles," Journal of Non-Crystalline Solids, vol. 357, pp. 136-139, 2011

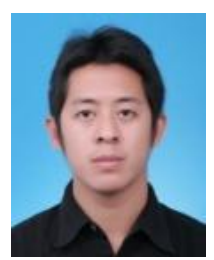

Andreas Aditya Hermawan was born on April 23, 1991 in Yogyakarta, Indonesia. He graduated from Monash University Sunway Campus Malaysia in 2013 as a bachelor holder of chemical engineering. At 2014, he started his post-graduate study as a master holder of engineering science at the Department of Civil Engineering under supervision of Dr. Amin Talei in Monash University Sunway Campus Malaysia. The topic of his research is about storm water bioretention process. From his past experience, he has done an internship study in JKS Engineering Sdn. Bhd. located in Kota Kemuning.

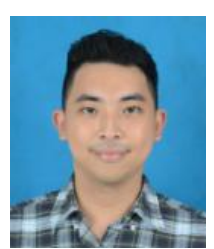

Tan Kok Bing was born on December 17, 1988 in Kuala Lumpur, Malaysia. He completed his undergraduate studies in 2012 and was admitted to the bachelor degree of engineering in the field of chemical engineering with Honours, which is awarded by Monash University Malaysia. Since 2012, he has been pursuing the doctor degree of philosophy course in Monash University Malaysia, under the supervision of Dr. Babak Salamatinia. His research interests include wastewater treatment, green technology and nano-materials. His job experience include an internship job from December 2010 to February 2011 in Jotun (M) Sdn. Bhd, Shah Alam, Selangor, and he was assigned to the industrial wastewater treatment plant division. Mr. Tan is also a member in the Institute of Chemical Engineer (ICHEME).

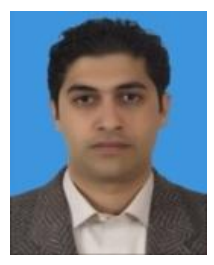

Babak Salamatinia obtained his first degree in Azad University-Arak Unit-Arak Iran as a chemical engineer majored in petrochemical industries in 2004. His interest in environmental issues led him to a research based studies in chemical engineering-bioprocess and environmental engineering in Universiti Sains Malaysia-Penang Malaysia (2006). His topic of research was "Development of Sorbent From Oil Palm Biomass for Heavy Metal Removal: A Case Study For $\mathrm{Cu}$ and $\mathrm{Zn}$ ”. He then furthered his studies as a PhD student in environmental catalysis doing research on "Intensified biodiesel production using ultrasonic-assisted heterogeneous catalytic process and product quality evaluation".

After graduating from USM, Babak Salamatinia was employed at a Lecturer Level in Monash University Malaysia and has been with this institution so far. He has supervised more than 15 final year project completions and currently he is a supervisor of 5 postgraduate students which 2 of them he is serving as a main supervisor. Dr. Babak Salamatinia has received several awards during his research life such as Malaysian Technology Expo. 2009 (MTE09). Silver medal, PWTC, Kuala Lumpur. 19-21 Feb 2009; BioMalaysia 2009. Bronze medal, KLCC, Kuala Lumpur. Oct 2009; Sangar Sanjung Award by Universiti Sains Malaysia for high quality publications $(2010,2011 \& 2012)$; top student Award by Iranian Embassy among all Iranian students in South East Asia (2007 and 2008); USM Fellowship Scheme (2008-2009). So far he has published 24 peer reviewed journals in field of adsorption, environment and biodiesel. 